\title{
Pathogenic and Nonpathogenic Lifestyles in Colletotrichum acutatum from Strawberry and Other Plants
}

\author{
Stanley Freeman, Sigal Horowitz, and Amir Sharon
}

First and second authors: Department of Plant Pathology, ARO., The Volcani Center, P.O. Box 6, Bet Dagan 50250, Israel; and third author: Department of Plant Sciences, Tel Aviv University, Tel Aviv 69978, Israel. Accepted for publication 6 July 2001.

\begin{abstract}
Freeman, S., Horowitz, S., and Sharon, A. 2001. Pathogenic and nonpathogenic lifestyles in Colletotrichum acutatum from strawberry and other plants. Phytopathology 91:986-992.

Anthracnose is one of the major fungal diseases of strawberry occurring worldwide. In Israel, the disease is caused primarily by the species Colletotrichum acutatum. The pathogen causes black spot on fruit, root necrosis, and crown rot resulting in mortality of transplants in the field. The host range and specificity of $C$. acutatum from strawberry was examined on pepper, eggplant, tomato, bean, and strawberry under greenhouse conditions. The fungus was recovered from all plant species over a

polymerase chain reaction (PCR)-specific primer amplification. $C$. acutatum was also isolated from healthy looking, asymptomatic plants of the weed genera Vicia and Conyza. Isolates that were recovered from the weeds caused disease symptoms on strawberry and were positively identified as $C$. acutatum by PCR. The habitation of a large number of plant species, including weeds, by $C$. acutatum suggests that, although it causes disease only on strawberry and anemone in Israel, this fungus can persist on many other plant species. Therefore, plants that are not considered hosts of $C$. acutatum may serve as a potential inoculum source for strawberry infection and permit survival of the pathogen between seasons.
\end{abstract} 3-month period but caused disease symptoms only on strawberry. Epiphytic and endophytic (colonization) fungal growth in the different plant species was confirmed by reisolation from leaf tissues and by
Additional keywords: anthracnose, C. gloeosporioides, detection, internal transcribed spacer region, quiescent infection, species-specific primers.
Species of the fungal plant pathogen Colletotrichum collectively cause anthracnose on strawberry (Fragaria $\times$ ananassa Duch.), which is a major disease of this crop worldwide. Principal pathogens known to be responsible for the disease are Colletotrichum acutatum J. H. Simmonds, $C$. fragariae Brooks, and $C$. gloeosporioides (Penz.) Penz. \& Sacc. in Penz. (teleomorph: Glomerella cingulata (Stoneman) Spauld. \& H. Schrenk) (19,28). C. acutatum was first observed and identified in Israel in 1995 (9). Plants infected with $C$. acutatum develop bud and crown rot, causing the collapse and death of the entire plant. In the nursery, lesions are formed on stolons that may girdle the runners, causing wilting and death of unrooted daughter plants. In addition, plants may develop symptoms of stunting and chlorosis, associated with root necrosis caused by $C$. acutatum (9).

Cross-infection potential has been reported among different species of Colletotrichum and genotypes of $C$. gloeosporioides on a variety of tropical, subtropical, and temperate fruit under artificial inoculation conditions $(1,2)$. To determine the potential of cross-infection in Colletotrichum spp., isolates from different crops were cross-inoculated on various hosts. In such experiments, isolates of $C$. acutatum and $C$. gloeosporioides from a variety of temperate fruit caused disease symptoms which were visually indistinguishable when inoculated on detached peach fruit (3). Likewise, in artificial inoculations of strawberry plants, $C$. trifolii isolates were either avirulent to moderately virulent on stolons, whereas one isolate of $C$. coccodes and additional isolates of $C$. gloeosporioides and $G$. cingulata were as virulent as $C$. fragariae on stolons (21). It was shown that $C$. gloeosporioides isolates from almond, apple, avocado, and mango, as well as $C$.

Corresponding author: S. Freeman; E-mail address: freeman@ netvision.net.il

Publication no. P-2001-0816-01R

(C) 2001 The American Phytopathological Society acutatum isolates from anemone, apple, and peach, infected detached fruit including apple (two cultivars), avocado, almond, mango, and nectarine (15). These results demonstrated cross-infection potential with two species, $C$. gloeosporioides (including representatives of distinct subpopulations from almond, apple, avocado, and mango) and C. acutatum (from apple and peach), on several fruit species (11). C. acutatum is a known pathogen of the ornamental anemone causing leaf-curl disease. In cross-inoculation experiments of anemone and strawberry, regardless of isolate source (anemone or strawberry), all anemone plants were killed within 14 days of inoculation, and typical anthracnose symptoms were observed on strawberry plants artificially inoculated with isolates from both hosts, resulting in eventual mortality of plants (16).

Numerous reports have indicated that strawberry anthracnose pathogens may originate from weed species (30). For example, $C$. fragariae was found attacking the weed Cassia obtusifolia L. (sicklepod, coffeweed) in Florida, causing typical disease symptoms (18). Furthermore, inoculation of strawberry with the Cassia isolates caused typical anthracnose symptoms, whereas isolates originating from strawberry were equally virulent on Cassia. Similarly, inoculation of Duchesnea indica (Andr.) Focke (wild strawberry), F. virginiana Duch. (Virginia wild strawberry), and Potentilla canadensis L. with $C$. fragariae caused anthracnose disease on these hosts $(4,6)$, indicating that strawberry anthracnose pathogens may have a wide host range.

Traditional methods may not be accurate enough for differentiating between species and subspecies of Colletotrichum; therefore, a number of molecular methods have been used to characterize populations of Colletotrichum. Arbitrarily primed polymerase chain reaction (ap-PCR) and limited restriction digest analyses of PCR-amplified ribosomal DNA (rDNA) were employed to differentiate between representative isolates of $C$. gloeosporioides and $C$. acutatum from a diverse host range, including strawberry 
$(10,14)$. Species-specific primers have been designed primarily according to dissimilarities in the sequence of the internal transcribe spacer (ITS) regions of representative isolates of Colletotrichum from different species and have subsequently been used to differentiate between $C$. acutatum and $C$. gloeosporioides from a broad host range and to detect latent infections in planta $(5,11,12)$.

In view of the fact that in Israel strawberry is cultivated adjacent to crops such as tomato, eggplant, pepper, and other vegetables, and that various weed species persist in the vicinity of strawberry, the potential for cross-inoculation was deemed of extreme importance. Furthermore, we found that an identical genotype of $C$. acutatum was recovered from natural field infections of both strawberry and anemone in Israel (16). Therefore, the main objectives of this work were to assess the persistence and interactions of $C$. acutatum on the main host, strawberry, and other plant species that may serve as potential inoculum sources for this pathogen under appropriate conditions.

\section{MATERIALS AND METHODS}

Fungal cultures and growth conditions. The monoconidial Colletotrichum cultures used in this study included Israeli isolates of $C$. acutatum (TUT-79, -110, -137, -149, and -5954) (9) and $C$. gloesporioides (CG-314) from strawberry, Vicia spp. (V-1, V-2, V3 , and V-4), and Conyza spp. (CONYZA) (isolated by the authors); U.S. isolate of C. gloeosporioides from strawberry (CG272) (14), and Israeli isolate of $C$. gloeosporioides from Limonium spp. (L-12) (isolated by the authors). The Vicia and Conyza isolates originated from the respective plants growing in a strawberry fruiting field in Israel infected with $C$. acutatum.

All fungi were cultured in the dark on modified Mathur's medium (MS; $0.1 \%$ yeast extract, $0.1 \%$ bactopeptone, $1 \%$ sucrose, $0.25 \% \quad \mathrm{MgSO}_{4} \cdot 7 \mathrm{H}_{2} \mathrm{O}, 0.27 \% \mathrm{KH}_{2} \mathrm{PO}_{4}, 2 \%$ agar) (31), supplemented for semiselective isolation of Colletotrichum, with $2.5 \mu \mathrm{g}$ (a.i.) of iprodione (Rovral 50WP, Rhone Poulenc, France), $0.1 \%$ lactic acid, and $25 \mathrm{mg}$ of ampicillin in 1 liter of sterile distilled water (9).

Plant and fruit inoculation procedures. Plants used in this study included: strawberry (cv. Malach), tomato (Lycopersicum esculantum Mill., cv. 149), eggplant (Solanum melongena L. var. esculentum Nees, cv. Classic), pepper (Capsicum annum L., cv. Maccabi), garden bean (Phaseolus vulgaris L., cv. Hilda), vetch (Vicia spp.), and horseweed (Conyza spp.). Seedlings of all the cultivated plants were received from Hishtil Nursery, Nahsholim, Israel. Plants in inoculation experiments were grown in pots (0.5-liter volume) in peat-vermiculite medium (vol/vol; $1: 1$ ), watered twice daily by overhead or drip irrigation (depending on the experimental design), and maintained in a greenhouse at $25^{\circ} \mathrm{C}$. The plants were artificially inoculated by spraying with a mixture of the $C$. acutatum isolates (TUT-79, -110, -137, -149, and -5954) at a concentration of $5 \times 10^{6}$ conidia/ml until run off, and maintained under $100 \%$ relative humidity by covering with plastic bags for $72 \mathrm{~h}$, as similarly described $(7,8,20)$. Leaves were sampled for assessment of survival and colonization at different time points starting immediately after spraying and until termination of the experiment. Pathogenicity assays of the Vicia (V-1, V-2, V-3, and V-4) and Conyza (CONYZA) C. acutatum isolates on strawberry and the respective weed species were performed separately for each individual isolate, as described below.

The fruit used in this study included apple (Malus domestica Borkh., cvs. Granny Smith, Golden Delicious, and Starking), pear (Pyrus communis L., cv. Spadona), peach (Prunus persica L., cv. Hermosa), and nectarine (P. persica L. Batsch var. nectarina, cv. Flamekiss), which were purchased at the local supermarket. Fruit were thoroughly washed with detergent to remove possible remnants of post harvest applied chemicals. The strawberry fruit (cv. Tamar) were obtained from untreated greenhouse plants at the Agricultural Research Organization. The various fruit were sur- face sterilized by submerging in 3\% sodium hypochlorite (Sigma, Rehovot, Israel) for $2 \mathrm{~min}$, washed extensively with sterile water, dried in a laminar flow hood, and either non-wound inoculated or wound inoculated by pinpricking. In vitro experiments were conducted to verify that surface sterilization killed all conidia and nongerminated melanized appressoria. For this purpose, conidia were germinated for 0 to $96 \mathrm{~h}$ until melanized appressoria were formed on a sterile petri dish containing a thin layer of liquid MS medium. Thereafter, the plates were surface sterilized as described, and no mycelial growth or fungal development was detected after pouring warm, solid MS medium into the plates. This experiment was repeated several times. In no case was there any recovery of the fungus, showing that surface sterilization eradicated $100 \%$ of fungal propagules (conidia, mycelium, and melanized appressoria) on the plastic as well as on leaf surfaces. Strawberry fruit were not surface sterilized before inoculation. Inoculation was performed by pipetting a $5-\mu l$ droplet of a conidial suspension $\left(5 \times 10^{6}\right.$ conidia $\left./ \mathrm{ml}\right)$ of a mixed culture of the $C$. acutatum isolates (TUT-79, -110, $-137,-149$, and -5954) from strawberry, C. gloeosporioides isolates (CG-314) from strawberry, and L-12 from Limonium spp. on the fruit surface. Lesion development on the fruit was measured daily and compared to water-inoculated controls.

Experimental design in inoculated greenhouse plants. The different experimental conditions included (i) inoculated plants maintained with overhead irrigation, (ii) inoculated plants maintained with drip irrigation, and (iii) noninoculated plants placed approximately $10 \mathrm{~cm}$ away from inoculated plants maintained with overhead irrigation. All experiments consisted of 24 plants of each species, four replicates of six plants per species, which were organized in a completely randomized design. Six leaves from each different plant species (one per different pot) were sampled at each period. Five water-inoculated plants of each host were used as controls. Each experiment was conducted twice, with similar results being recorded.

Survival of $\boldsymbol{C}$. acutatum from strawberry on plants. Leaves were sampled for inoculum survival and colonization before (day 0 or time 0 ), after removal of the plastic coverings from the inoculated plants (day 3), and approximately every 7 days thereafter. New foliage emerging postinoculation was also sampled as the leaves developed to evaluate inoculum dispersal. The leaves were inserted into a plastic Falcon tube containing $10 \mathrm{ml}$ of sterile water and mixed thoroughly for $2 \mathrm{~min}$ by vortexing, to remove conidia from the leaf surface. Microscopic and dilution plating experiments revealed that 80 to $95 \%$ of all applied conidia were removed from the leaf surface by this treatment after repeating these procedures at least three times at various periods from 0 to 4 days postinoculation. Therefore, percent conidial survival was an underestimation of the actual rate of survival. The leaf was removed from the tube after vortexing and used for evaluating pathogen colonization. The tube and contents were then centrifuged at $6,500 \times g$, the conidial pellet resuspended in $1 \mathrm{ml}$ of water, and conidia were quantified by dilution plating on the semiselective Colletotrichum medium (9). The area of each sampled leaf was measured in order to quantify conidia per square centimeter with survival calculated at each period for each plant species.

Colonization of different plant species by $C$. acutatum from strawberry. After conidia were washed from the sampled leaf, the leaf was surface sterilized by submerging in 3\% sodium hypochlorite for $2 \mathrm{~min}$, washing in sterilized $\mathrm{ddH}_{2} \mathrm{O}$ for $1 \mathrm{~min}$, and drying in a laminar flow hood. All fungal propagules (conidia, mycelium, and nongerminated melanized appressoria) upon the leaf surface were killed by this treatment, including conidia that were not entirely removed by the washing and vortexing treatments, as previously described. Thereafter, the leaf was divided into 10 parts and plated on the semiselective Colletotrichum medium to determine percent colonization.

Extraction, isolation, and purification of fungal DNA. For fungal DNA extraction, liquid cultures comprising $100 \mathrm{ml}$ of MS 
medium devoid of agar in 250-ml Erlenmeyer flasks were inoculated with five mycelial disks that were cut out from colony margins. The cultures were agitated for 5 to 6 days on a rotary shaker at $150 \mathrm{rpm}$ and maintained at $25^{\circ} \mathrm{C}$. Mycelia from $100-\mathrm{ml} \mathrm{MS}$ liquid cultures were collected by vacuum filtration and lyophilized until dry. DNA was extracted and purified as previously described (13). The DNA was dissolved in $0.5 \mathrm{ml}$ of TE buffer (10 mM Tris$\mathrm{HCl}, 1 \mathrm{mM}$ EDTA; $\mathrm{pH} 8.0)$ to an approximate concentration of 200 to $500 \mu \mathrm{g} / \mathrm{ml}$ and diluted to a concentration of 10 to $100 \mathrm{ng} / \mu \mathrm{l}$ for PCR reactions.

Extraction, isolation, and purification of plant DNA or pathogen DNA in plants. Plants (strawberry, tomato, eggplant, pepper, and bean) were inoculated under greenhouse conditions as previously described. Three leaves per host plant were sampled daily, washed thoroughly in running tap water, and vortexed to remove conidia from the leaf surface. DNA was extracted essentially as described (29). Leaf tissue (1 g) was ground in $5 \mathrm{ml}$ of cetyltrimethylammonium bromide (CTAB) buffer (2\% CTAB, $1.4 \mathrm{M} \mathrm{NaCl}, 0.2 \% \beta$-mercaptoethanol, $20 \mathrm{mM}$ Tris-HCl, $\mathrm{pH} \mathrm{8.0)}$ and a $150-\mu \mathrm{l}$ chloroform/isoamylalchohol (24:1) solution was added and heated at $65^{\circ} \mathrm{C}$ for $30 \mathrm{~min}$. The contents were cooled to room temperature and a $850-\mu$ chloroform/isoamylalchohol (24:1) solution was added and mixed thoroughly. The water and organic phases were separated by centrifugation at $14,000 \times g$ and the water phase was collected and transferred to a clean Falcon tube. Two volumes of cold $\left(-20^{\circ} \mathrm{C}\right)$ ethanol $(95 \%)$ were added to the tubes and centrifuged at $14,000 \times g$ to precipitate the DNA. The supernatant was discarded and the precipitate was washed with an equal volume of $76 \%$ ethanol to $0.2 \mathrm{M}$ sodium acetate solution for $5 \mathrm{~min}$, then centrifuged at $10,000 \times g$ for $5 \mathrm{~min}$. The supernatant was discarded and the DNA pellet was dissolved in $0.5 \mathrm{ml}$ of TE buffer, $\mathrm{pH}$ 8.0. To further purify the DNA, a volume of $0.25 \mathrm{ml}$ of $7.5 \mathrm{~N}$ ammonium acetate was added to the DNA pellet and incubated on ice for $20 \mathrm{~min}$. Thereafter, the solution was centrifuged at

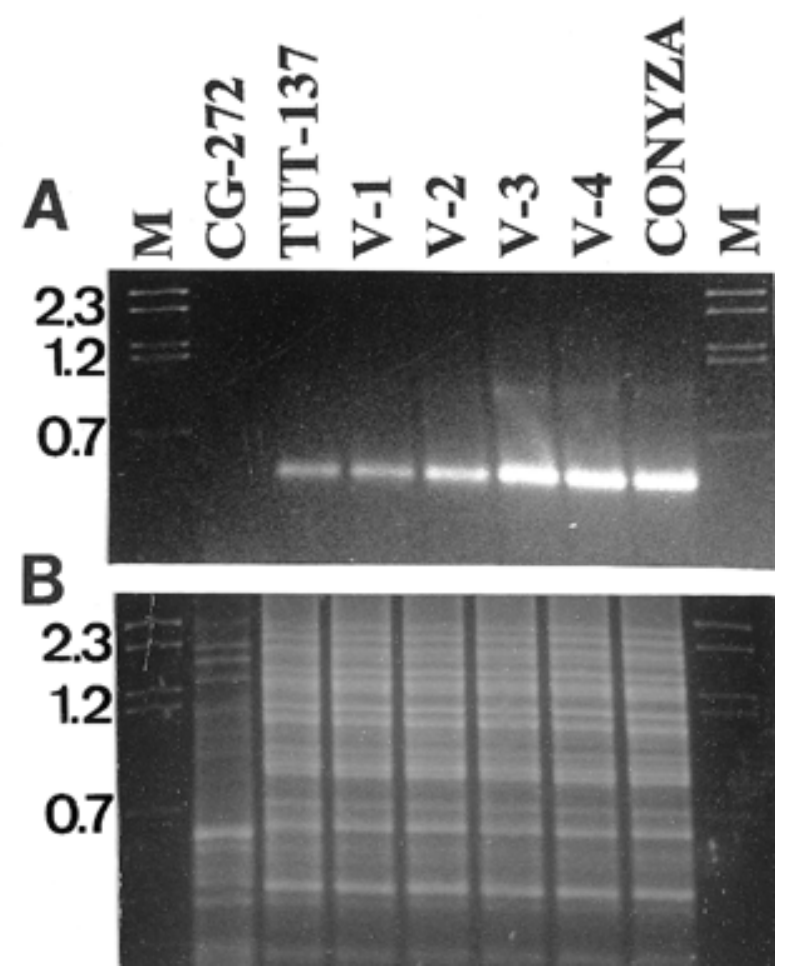

Fig. 1. Polymerase chain reaction amplification products using species-specific primers for $\mathbf{A}$, Colletotrichum acutatum and $\mathbf{B}$, microsatellite primer $(\mathrm{GACAC})_{3}$ of genomic DNA from $C$. gloeosporioides from strawberry (isolate CG-272), and C. acutatum isolates from strawberry (TUT-137A), Vicia spp. (V-1, V-2, V-3, and V-4), and Conyza spp. (CONYZA). Lane M: DNA markers with sizes in kilobases.
$10,000 \times g$ for $20 \mathrm{~min}$ and the supernatant was collected. Isopropanol was added to the supernatant $(0.6 \mathrm{vol} / \mathrm{vol})$ and incubated on ice for $20 \mathrm{~min}$. The solution was then centrifuged at 5,000 $\times g$ for $5 \mathrm{~min}$ and the precipitated DNA was collected and dissolved in $0.5 \mathrm{ml}$ of TE buffer. The TE buffer containing DNA was mixed in $2 \mathrm{vol}$ of $95 \%$ ethanol and incubated on ice for $30 \mathrm{~min}$. The DNA was precipitated to a final concentration with $0.1 \mathrm{M} \mathrm{NaCl}$, by centrifugation at $5,000 \times g$ for $5 \mathrm{~min}$, dissolved in $0.5 \mathrm{ml}$ of TE buffer, and used in the PCR reactions for pathogen detection in planta, as described below.

PCR amplification. For arbitrarily primed PCR (ap-PCR), primers were derived from minisatellite or repeat sequences as follows: CAGCAGCAGCAGCAG (26), GACACGACACGACAC (17), and GACAGACAGACAGACA (32). In the text, these primers have been designated $(\mathrm{CAG})_{5},(\mathrm{GACAC})_{3}$, and $(\mathrm{GACA})_{4}$, respectively. PCR primers for detection of the pathogen in planta
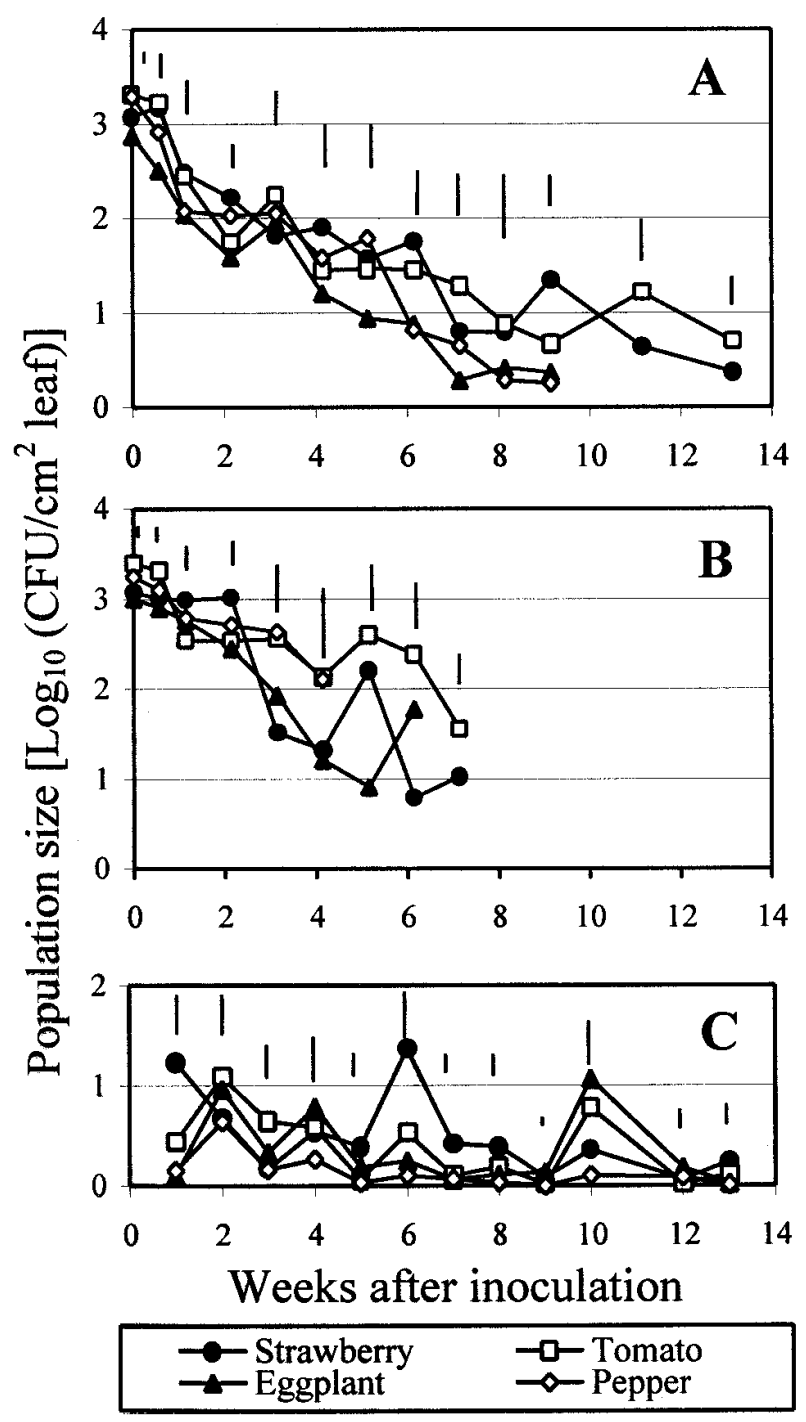

Fig. 2. Survival of Colletotrichum acutatum from strawberry on strawberry, tomato, eggplant, and pepper plants in the greenhouse. Plants were maintained with $\mathbf{A}$, overhead or $\mathbf{B}$, drip irrigation regimes. $\mathbf{C}$, Noninoculated plants were maintained with overhead irrigation in the vicinity of inoculated plants. Inoculated plants were placed $10 \mathrm{~cm}$ away from noninoculated plants. Leaves were picked at each sampling period and the conidia were washed from the surface and quantified by dilution plating. Data from each sampling period (means of six sampled leaves each per plant species) were analyzed by least significant difference and the values denoted as vertical bars above each point, according to the Tukey-Kramer multiple comparison test at a significance level of $P<0.05$. Distances between symbols at each point that are larger than the vertical bar are significant. 
included the ITS4 primer (TCCTCCGCTTATTGATATGC) coupled with the specific primer for $C$. acutatum (CaInt2) (GGGGAAGCCTCTCGCGG) (5). PCR reactions were performed in a total volume of $20 \mu \mathrm{l}$, containing 10 to $100 \mathrm{ng}$ of genomic DNA; $50 \mathrm{mM} \mathrm{KCl} ; 10 \mathrm{mM}$ Tris- $\mathrm{HCl} ; 0.2 \mathrm{mM}$ each of dATP, dCTP, dGTP, and dTTP; $1.5 \mathrm{mM} \mathrm{MgCl} 2,1$ unit of Taq DNA polymerase (Promega Corp., Madison, WI), and $1 \mu \mathrm{M}$ primer. The reactions were incubated in a PTC-100 thermocycler (MJ Research Inc., Watertown, MA) starting with $5 \mathrm{~min}$ of denaturation at $95^{\circ} \mathrm{C}$. For ap-PCR, this was followed by 30 cycles consisting of $30 \mathrm{~s}$ at $95^{\circ} \mathrm{C}, 30 \mathrm{~s}$ at either $60^{\circ} \mathrm{C}$ (for $(\mathrm{CAG})_{5}$ ) or $48^{\circ} \mathrm{C}$ (for $(\mathrm{GACA})_{4}$ and $(\mathrm{GACAC})_{3}$ ) and $1.5 \mathrm{~min}$ at $72^{\circ} \mathrm{C}$. C. acutatum-specific PCR reactions were performed under reaction conditions for primer $(\mathrm{CAG})_{5}$ with $0.5 \mu \mathrm{M}$ ITS4 primer coupled with $0.5 \mu \mathrm{M}$ primer $\mathrm{CaInt} 2$. Amplification products were separated in agarose gels $(1.8 \%$ wt/vol; $15 \times 10 \mathrm{~cm}, \mathrm{WXL})$ in Tris-acetate-EDTA buffer (27), electrophoresed at $80 \mathrm{~V}$ for $2 \mathrm{~h}$, stained with ethidium bromide, and viewed under UV light for detection of amplification products.

Statistical analyses of data. Data from plant and fruit inoculation experiments at each sampling or inoculation period were analyzed by least significant difference (LSD) of the means according to the Tukey-Kramer multiple comparison test at a significance level of $P<0.05$, using the JMP software package (version 3.2.6; SAS Institute, Inc., Cary, NC).

\section{RESULTS}

C. acutatum from weed species. Species-specific primer analysis identified four isolates from Vicia spp. and one from Conyza spp. as C. acutatum (Fig. 1A). All isolates possessed uniform ap-PCR banding patterns similar to the reference culture TUT-137 of $C$. acutatum from strawberry and different from that of C. gloeosporioides (Cg-272) also from strawberry, using primers $(\mathrm{GACAC})_{3}$ (Fig. 1B), (GACA) $)_{4}$, and $(\mathrm{CAG})_{5}$ (data not shown). All five $C$. acutatum weed isolates were pathogenic on strawberry, causing $100 \%$ plant mortality under artificial inoculation conditions in the greenhouse; however, no anthracnose symptoms were observed on the inoculated weed species (data not shown).

Survival of . acutatum on inoculated plants. Strawberry, eggplant, tomato, and pepper plants were inoculated with a conidial suspension of $C$. acutatum from strawberry. Conidia were recovered from all plants over a 2- to 3-month period, with either overhead or drip irrigation regimes (Fig. 2). The number of conidia recovered from strawberry was similar to that recovered from the other plants at all time points, and in most cases was insignificant $(P<0.05)$ for the different plant species, although disease symptoms were observed only on strawberry. Significant numbers of conidia were recovered from the plants even at the end of the experiment, indicating that the survival potential of the fungus on all plant species was well over 3 months. Leaves were picked at various time points after inoculation and conidial survival on the surface was quantified (conidia per square centimeter of leaf tissue). With overhead irrigation conditions, conidia survived on all inoculated plant leaves, but declined approximately threefold over a 13-week period (Fig. 2A). Similarly, under drip irrigation, conidia survived on host leaves, but declined approximately twofold during the 7-week experimentation period (Fig. 2B).

Survival of conidia was monitored on inoculated plants on the new foliage sampled postinoculation from 6 and 4 weeks with overhead and drip irrigation conditions, respectively. Low numbers of conidia ( $<10$ conidia per $\mathrm{cm}^{2}$ leaf tissue) were recovered from emerging new foliage of all plant species tested, under both irrigation regimes for the duration of the experiments, 13 and 11 weeks, respectively (data not shown).

Survival of conidia was also monitored in noninoculated plants located approximately $10 \mathrm{~cm}$ away from inoculated plants using overhead irrigation (Fig. 2C). The number of conidia was general- ly low and fluctuated during the experiments, ranging between 0 and 30 conidia per $\mathrm{cm}^{2}$ of leaf area for all plants; in most cases, this was insignificant $(P<0.05)$ between species. Overall, the numbers of conidia decreased with time and few conidia per square centimeter of leaf area remained at the end of the experiment, after 12 weeks (Fig. 2C).

Colonization of plants by $\boldsymbol{C}$. acutatum. Strawberry, eggplant, tomato, and pepper plants were inoculated with a conidial suspension of $C$. acutatum from strawberry and maintained with either overhead or drip irrigation regimes. Leaves were picked at various time points after inoculation, washed to remove conidia, surface sterilized, and plated on the semiselective Colletotrichum medium to test for presence of the fungus within the tissue. The fungus was detected within leaf tissues of all plant species regardless of the irrigation regime and, in all cases, differences between colonization of the various plants was insignificant $(P<0.05)$ (Fig. $3 \mathrm{~A}$ and $\mathrm{B})$. With overhead irrigation, recovery of the pathogen ranged between 90 and $100 \%$ in examined tissues over a 6-week period postinoculation (Fig. 3A). Colonization declined over time, but remained above $50 \%$ in the examined tissues until the end of the experiment.

Under drip irrigation, the pathogen was isolated from within all plant leaves with percent colonization ranging from 50 to $100 \%$ during the first 5 weeks postinoculation (Fig. 3B). Levels of

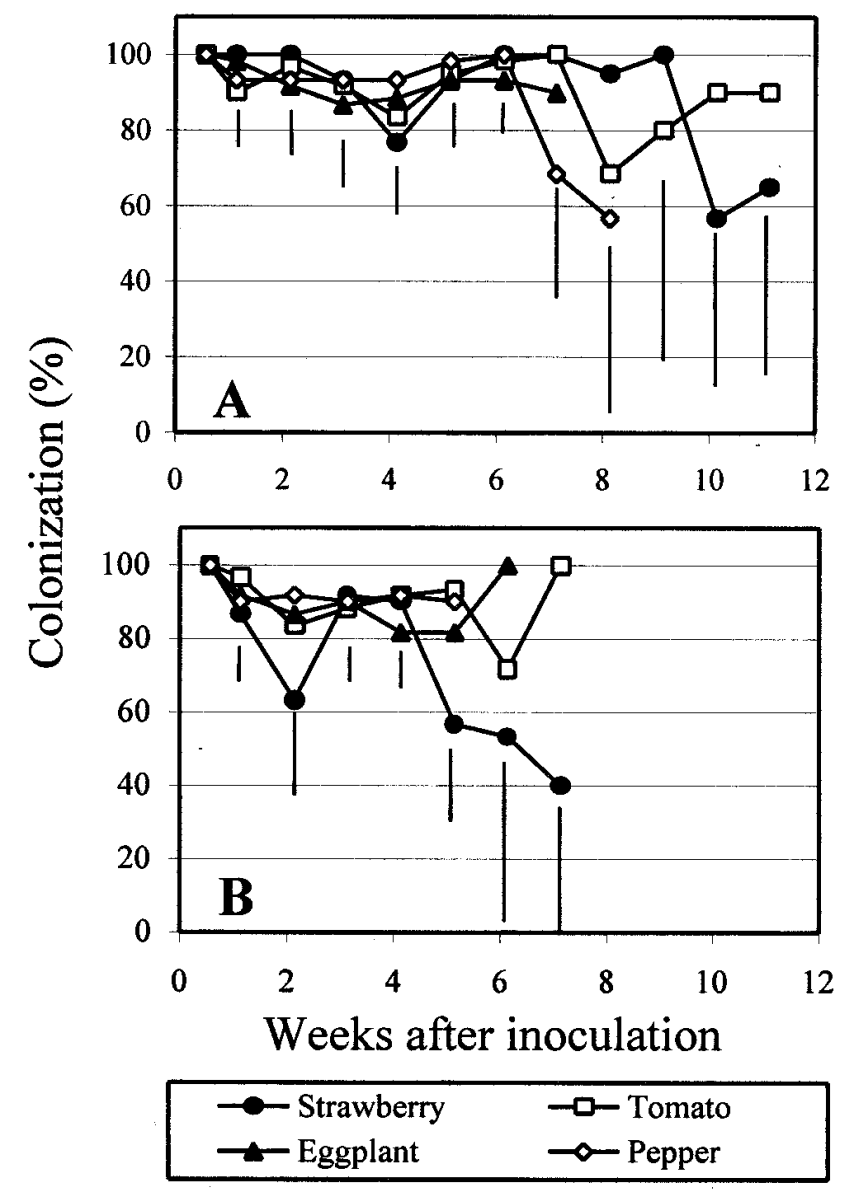

Fig. 3. Colonization of strawberry, tomato, eggplant, and pepper by Colletotrichum acutatum from strawberry. Plants were maintained with $\mathbf{A}$, overhead and $\mathbf{B}$, drip irrigation in the greenhouse. At each sampling period, leaves were picked, conidia were washed from the surface, and the leaf surface was sterilized. Thereafter, percent colonization was determined by dividing the leaf into 10 parts and plating. Data from each sampling period (means of six sampled leaves each per plant species) were analyzed by least significant difference and the values denoted as vertical bars above each point, according to the Tukey-Kramer multiple comparison test at a significance level of $P<0.05$. Distances between symbols at each point that are larger than the vertical bar are significant. 
colonization remained between 80 and $100 \%$ in eggplant and tomato, whereas colonization of strawberry decreased to approximately $40 \%$ by the end of the experiment (Fig. 3B).

Pathogen detection in planta with $C$. acutatum-specific primers. The pathogen was readily detected in artificially inoculated strawberry, tomato, eggplant, and pepper leaf tissues by PCR amplification (Fig. 4). Species-specific primer analysis was accurate in detecting $C$. acutatum in planta by amplification of the specific band of $490 \mathrm{bp}$., which was observed from $24 \mathrm{~h}$ postinoculation until 7 days thereafter in the control DNA of isolate TUT-137 of C. acutatum, inoculated strawberry and tomato (Fig. 4A), and eggplant and pepper (Fig. 4B). No amplification product was observed in noninoculated control leaf tissues. Similar results were obtained in infected bean leaf tissue (data not shown).

Cross-infection potential. Strawberry fruit were wound or non-wound inoculated with isolates of $C$. acutatum and $C$. gloeosporioides from strawberry and $C$. gloeosporioides from Limonium spp. In general, no significant differences $(P<0.05)$ were detected in lesion size caused by the strawberry pathogens on fruit compared with those of the $C$. gloeosporioides Limonium isolate L-12, 9 days after either wound or non-wound inoculations (Fig. 5).

In cross-inoculation experiments of various fruit with $C$. $a c u-$ tatum from strawberry, lesions developed in time on all inoculated, wounded fruit, whereas unwounded pear and nectarine showed only minor lesions (Table 1). Wounding of strawberry and peach did not significantly $(P<0.05)$ increase lesion size compared with that of pear and nectarine. No symptoms were observed on inoculated, unwounded apples.

\section{DISCUSSION}

Anthracnose disease caused by $C$. acutatum has become one of the major fungal pathogens of strawberry worldwide. In Israel, the fungus was first reported in 1995 (9) and has since spread to most strawberry cultivation areas within the country. Mother plants are
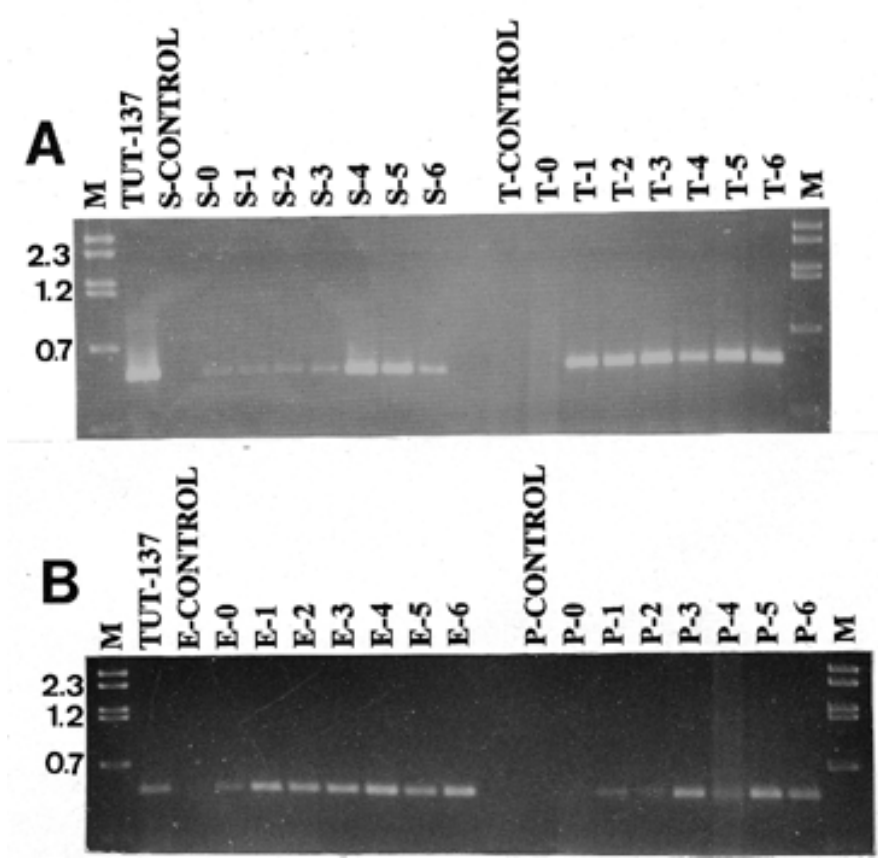

Fig. 4. Polymerase chain reaction amplification products using species-specific primers for Colletotrichum acutatum. A, C. acutatum isolate TUT-137, noninoculated (S-CONTROL), and inoculated strawberry at days 0 to 6 (S-0, S-1, S-2, S-3, S-4, S-5, and S-6), and respective treatments in tomato (T). B, Respective treatments in eggplant (E) and pepper (P) leaves. Lane M: DNA markers with sizes in kilobases. commonly infected in the nursery; however, symptoms may develop later during daughter plant establishment, after planting. Such mother plants are considered the primary inoculum source on which the fungus proliferates and then spreads to daughter plants in the nursery, and eventually to production fields via transplants. While plant infection in the nursery is an important source of inoculum, there might be additional sources for dissemination of the fungus and initiation of new epidemics (e.g., other plant species). Strawberry is cultivated alongside tomato, eggplant, pepper, and other vegetable crops, and various weeds persist in the vicinity of nurseries and near or within strawberry production fields in Israel. The main objectives of this study were to assess potential for cross-inoculation, survival, and pathogenicity of $C$. acutatum on strawberry and other plants that may serve as a primary inoculum source under greenhouse conditions.

It has been reported on numerous occasions that cross-infection potential exists within the genus Colletotrichum, and that the fungus may exist in different nonpathogenic, symbiotic lifestyles (25). In this study, we have shown that $C$. acutatum from strawberry is able to cause lesions on various fruit, with or without wounding (Fig. 5). Therefore, under conditions where hosts are susceptible to $C$. acutatum, for example peach, apple, and anemone $(1,3,11,16)$, special care should be taken that the pathogen does not spread from one host to the other, especially where the different hosts are cultivated in close proximity. However, it should be emphasized that the conditions employed during artificial inoculations, such as high inoculum concentration, detached leaves or fruit, and optimized humidity and temperature, may result in cross-infections not observed under field conditions. This may be exemplified with $C$. gloeosporioides pathogenic to Limonium spp., which is grown in the desert far from strawberry cultivation areas, but caused a hypervirulent reaction on artificially inoculated strawberry (Fig. 5). Alternatively, postharvest infections are readily achieved by inoculation of detached fruit and plant tissue which is widely accepted for determining pathogenicity and virulence during storage conditions $(15,24)$.
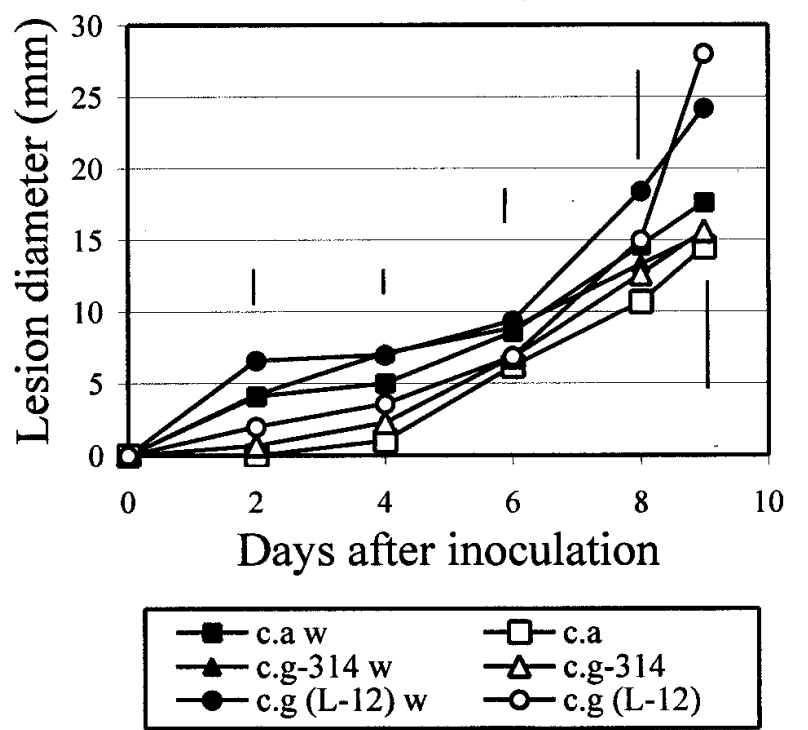

Fig. 5. Inoculation of strawberry (cv. Tamar) fruit with isolates of Colletotrichum acutatum (c.a) from strawberry (s), and C. gloeosporioides (c.g) from strawberry (s) and Limonium spp. (1). Fruit were inoculated by pipetting $5 \mu \mathrm{l}$ of $5 \times 10^{6} \mathrm{conidia} / \mathrm{ml}$ of each isolate on the surface, either without or with wounding (w) by pinpricking. Data from each inoculation period (lesion size of each of 10 different fruit) were analyzed by least significant difference and the values denoted as vertical bars above each point, according to the Tukey-Kramer multiple comparison test at a significance level of $P<0.05$. Distances between symbols at each point that are larger than the vertical bar are significant. 
In inoculations under controlled greenhouse conditions, $C$. acutatum from strawberry was isolated from inoculated plants that did not show disease symptoms, but maintained virulence on strawberry. The fungus was detected by a plating method both on and inside inoculated leaves at various time points after plant inoculation. The authenticity of the isolates as $C$. acutatum was validated by PCR using $C$. acutatum-specific primers (29). The PCR technique proved accurate and sensitive enough in detecting the pathogen in inoculated tissues within $24 \mathrm{~h}$ postinoculation. Therefore, this method is useful in detecting $C$. acutatum on and within the tissues of various plant species, indicating that the fungus can exhibit epiphytic and endophytic lifestyles without causing visible disease symptoms. The PCR and fungal isolation data indicate that the pathogen can remain viable for extended periods of time in the tissues of various plants species without inducing disease symptoms. Although the experiments were terminated after 3 months (for technical reasons), the final levels of inoculum in the examined tissues and the decay curves suggest that the pathogen had the potential to inhabit the infected plants for much longer periods of time. Furthermore, it has been shown that $C$. acutatum from strawberry can survive for 9 months within plant debris in soil (8).

Recently, it has been reported by Leandro et al. (20) that secondary conidia are formed on strawberry leaves in the absence of infection or host penetration. In this work, symptoms of disease were not detected on plants such as tomato, eggplant, pepper, and bean, but conidia survived on the leaf surfaces, possibly as secondary inoculum or within the cuticular and subepidermal leaf tissues. The pathogen was also capable of surviving on foliage of plants maintained under drip irrigation conditions for at least 7 weeks (Fig. 2B), indicating that low moisture conditions were not detrimental to inoculum viability even in the nonpathogenic interactions.

C. acutatum was isolated from two weeds, Conyza spp. and Vicia spp., that infested strawberry fields. The weed isolates were similar to those from strawberry as proved by PCR analysis (Fig. 1) and caused typical anthracnose symptoms on strawberry. Thus, not only crop plants but also weeds may be colonized by $C$. $a c u$ tatum. This is in accordance with the detection of $C$. fragariae, pathogenic to strawberry, on the weeds chickweed, coffeeweed, sicklepod, fiddleneck, and vetch growing in containers and in and around nurseries in Florida $(4,18,19,30)$. Likewise, strawberry and anemone that are cultivated in close proximity in Israel were found infected by an identical genotype of C. acutatum (16).

Inoculum of Colletotrichum spp. pathogenic to strawberry is usually distributed by splash dispersal, either via overhead irriga-

TABLE 1. Lesion development on various fruit artificially inoculated with Colletotrichum acutatum from strawberry

\begin{tabular}{|c|c|c|c|}
\hline Host & Cultivar & Treatment $^{\mathrm{a}}$ & Lesion $(\mathrm{mm})^{b}$ \\
\hline Strawberry & Yael & Unwounded & $14.5 \pm 1.6$ \\
\hline Strawberry & Yael & Wounded & $17.6 \pm 1.4$ \\
\hline Pear & Spadona & Unwounded & $9.0 \pm 3.0$ \\
\hline Pear & Spadona & Wounded & $37.5 \pm 1.3$ \\
\hline Peach & Hermosa & Unwounded & $24.2 \pm 2.1$ \\
\hline Peach & Hermosa & Wounded & $26.0 \pm 1.4$ \\
\hline Nectarine & Flamekiss & Unwounded & $2.4 \pm 1.0$ \\
\hline Nectarine & Flamekiss & Wounded & $32.4 \pm 1.0$ \\
\hline Apple & Golden Delicious & Wounded & $48.0 \pm 1.7$ \\
\hline Apple & Starking & Wounded & $35.5 \pm 2.6$ \\
\hline Apple & Granny Smith & Wounded & $27.6 \pm 3.3$ \\
\hline $\mathrm{LSD}^{\mathrm{c}}$ & $\ldots$ & $\ldots$ & 9.4 \\
\hline
\end{tabular}

${ }^{a}$ Fruit were either wounded or unwounded and inoculated with a 5- $\mu$ drop of a mixed conidial suspension of $C$. acutatum isolates (TUT-79, -110, $-137,-149$, and -5954$)$ at a concentration of $5 \times 10^{6}$ conidia per ml.

${ }^{\mathrm{b}}$ Lesions were measured 9 days following inoculation. Data are means \pm standard error.

${ }^{c}$ Data are the means of each of ten lesions per fruit, analyzed by least significant difference (LSD) according to the Tukey-Kramer multiple comparison test at a significance level of $(P<0.05)$. tion or by rain $(22,23)$. In our experiments, it was shown that, under greenhouse conditions, overhead irrigation contributed to dispersal of inoculum to noninoculated host plants (Fig. 2C). However, conidia survived and colonized equally well on the surface of drip- compared with overhead-irrigated plants. (Figs. 2 and 3). This may be explained by secondary sporulation (20) contributing to conidial survival and proliferation on the leaf surface during drip irrigation as opposed to conidial removal from the leaf surface during overhead irrigation.

Although C. acutatum survives in the soil, on plant debris, and in fumigated field soil (8), it is assumed that the main source of inoculum usually originates on infected strawberry plant material from the nursery (9). However, in nurseries or in production fields, the pathogen may be introduced in contaminated soil, on field equipment, or may be splash dispersed or blown in from surrounding vegetation that may carry the fungus, albeit without visible symptoms (30). This work has shown that $C$. acutatum from strawberry can survive and colonize many other plant species under controlled greenhouse conditions without causing disease, exhibiting epiphytic, endophytic, and nonpathogenic lifestyles. These findings emphasize that various crop plants, including weeds, may serve as a potential inoculum source of $C$. $a c u$ tatum. The contribution of inoculum that originates in such plants to development of anthracnose disease in strawberry under field conditions and in dispersal of the pathogen from season to season will need further investigation.

\section{ACKNOWLEDGMENTS}

Contribution from the Agricultural Research Organization, The Volcani Center, Bet Dagan, Israel, No. 532/00. This research was supported in part by research grant award IS-2825-97 from BARD, The United States-Israel Binational Agricultural Research and Development Fund, and European Commission FAIR CT 98-4140 grant awarded to S. Freeman. We thank D. Shtienberg for assistance with statistical analyses.

\section{LITERATURE CITED}

1. Adaskaveg, J. E., and Hartin, R. J. 1997. Characterization of Colletotrichum acutatum isolates causing anthracnose of almond and peach in California. Phytopathology 87:979-987.

2. Alahakoon, P. W., Brown, A. E., and Sreenivasaprasad, S. 1994. Crossinfection potential of genetic groups of Colletotrichum gloeosporioides on tropical fruits. Physiol. Mol. Plant Pathol. 44:93-103.

3. Bernstein, B., Zehr, E. I., Dean, R. A., and Shabi, E. 1995. Characteristics of Colletotrichum from peach, apple, pecan, and other hosts. Plant Dis. 79:478-482.

4. Brooks, A. N. 1931. Anthracnose of strawberry caused by Colletotrichum fragariae, n. sp. Phytopathology 21:739-744.

5. Brown, A. E., Sreenivasaprasad, S., and Timmer, L. W. 1996. Molecular characterization of slow-growing orange and Key lime anthracnose strains of Colletotrichum from citrus as C. acutatum. Phytopathology 86:523-527.

6. Delp, B. R., and Milholland, R. D. 1981. Susceptibility of strawberry cultivars and related species to Colletotrichum fragariae. Plant Dis. 65:421-423.

7. Denoyes-Rothan, B., and Guérin, G. 1995. Comparison of six inoculation techniques with Colletotrichum acutatum on cold stored strawberry plants and screening for resistance to this fungus in French strawberry collections. Eur. J. Plant Pathol. 102:615-621.

8. Eastburn, D. M., and Gubler, W. D. 1990. Strawberry anthracnose: Detection, and survival of Colletotrichum acutatum in soil. Plant Dis. 74:161-163.

9. Freeman, S., and Katan, T. 1997. Identification of Colletotrichum species responsible for anthracnose and root necrosis of strawberry in Israel. Phytopathology 87:516-521.

10. Freeman, S., Katan, T., and Shabi, E. 1996. Differentiation between Colletotrichum gloeosporioides from avocado and almond using molecular and pathogenicity tests. Appl. Environ. Microbiol. 62:10141020 .

11. Freeman, S., Katan, T., and Shabi, E. 1998. Characterization of Colletotrichum species responsible for anthracnose diseases of various fruits. Plant Dis. 82:596-605.

12. Freeman, S., Minz, D., Jurkevitch, E., Maymon, M., and Shabi, E. 2000. 
Molecular analyses of Colletotrichum species from almond and other fruits. Phytopathology 90:608-614.

13. Freeman, S., Pham, M., and Rodriguez, R. J. 1993. Molecular genotyping of Colletotrichum species based on arbitrarily primed PCR, A+Trich DNA, and nuclear DNA analyses. Exp. Mycol. 17:309-322.

14. Freeman, S., and Rodriguez, R. J. 1995. Differentiation of Colletotrichum species responsible for anthracnose of strawberry by arbitrarily primed PCR. Mycol. Res. 99:901-905.

15. Freeman, S., and Shabi, E. 1996. Cross-infection of subtropical and temperate fruits by Colletotrichum species from various hosts. Physiol. Mol. Plant Pathol. 49:395-404.

16. Freeman, S., Shabi, E., and Katan, T. 2000. Characterization of Colletotrichum acutatum causing anthracnose disease of anemone (Anemone coronaria L.). Appl. Environ. Microbiol. 66:5267-5272.

17. Gupta, M., and Filner, P. 1991. Microsatellites amplify highly polymorphic DNA bands in SPAR of plant DNA. Int. Soc. Plant Mol. Biol. Abstr. 1705, Tucson, AZ.

18. Howard, C. M., and Albregts, E. E. 1973. Cassia obtusifolia, a possible reservoir for inoculum of Colletotrichum fragariae. Phytopathology 63:533-534.

19. Howard, C. M., Maas, J. L., Chandler, C. K., and Albregts, E. E. 1992. Anthracnose of strawberry caused by the Colletotrichum complex in Florida. Plant Dis. 76:976-981.

20. Leandro, L. F. S., Gleason, M. L., and Nutter, F. W., Jr. 2001. Germination and sporulation of Colletotrichum acutatum on symptomless strawberry leaves. Phytopathology 91:659-664.

21. Maas, J. L., and Howard, C. M. 1985. Variation of several anthracnose fungi in virulence to strawberry and apple. Plant Dis. 69:164-166.

22. Madden, L. V., Yang, X., and Wilson, L. L. 1996. Effects of rain intensity on splash dispersal of Colletotrichum acutatum. Phytopathology 86:864-874.
23. Ntahimpera, N., Wilson, L. L., Ellis, M. A., and Madden, L. V. 1999. Comparison of rain effects on splash dispersal of three Colletotrichum species infecting strawberry. Phytopathology 89:555-563.

24. Prusky, D., and Keen, N. T. 1993. Involvement of preformed antifungal compounds in the resistance of subtropical fruits to fungal decay. Plant Dis. 77:114-119.

25. Rodriguez, R. J., and Redman, R. S. 2000. Colletotrichum as a model system for defining the genetic basis of fungal symbiotic lifestyles. Pages 114-130 in: Colletotrichum: Host Specificity, Pathology, and Host-Pathogen Interactions. D. Prusky, S. Freeman, and M. D. Dickman, eds. The American Phytopathological Society, St. Paul, MN.

26. Rodriguez, R. J., and Yoder, O. C. 1991. A family of conserved repetitive DNA elements from the fungal plant pathogen Glomerella cingulata (Colletotrichum lindemuthianum). Exp. Mycol. 15:232-242.

27. Sambrook, J., Fritsch, E. F., and Maniatis, T. 1989. Molecular Cloning: A Laboratory Manual. 2nd ed. Cold Spring Harbor Laboratory, Cold Spring Harbor, NY.

28. Smith, B. J., and Black, L. L. 1990. Morphological, cultural, and pathogenic variation among Colletotrichum species isolated from strawberry. Plant Dis. 74:69-76.

29. Sreenivasaprasad, S., Sharada, K., Brown, A. E., and Mills, P. R. 1996. PCR-based detection of Colletotrichum acutatum on strawberry. Plant Pathol. 45:650-655.

30. Strand, L. L. 1994. Integrated pest management for strawberries. University of California, Oakland, CA.

31. Tu, J. C. 1985. An improved Mathur's medium for growth, sporulation and germination of Colletotrichum lindemuthianum. Microbiosis 44:8793.

32. Weising, K., Weigand, F., Driesel, A. J., Kahl, A. J., Zischer, H., and Epplen, J. T. 1989. Polymorphic simple GATA/GACA repeats in plant genomes. (Abstr.) Nucleic Acids Res. 17:10128. 